\title{
Slow-Wave Sleep-Imposed Replay Modulates Both Strength and Precision of Memory
}

\author{
Dylan C. Barnes ${ }^{1,2}$ and Donald A. Wilson ${ }^{1,2,3}$ \\ ${ }^{1}$ Emotional Brain Institute, Nathan Kline Institute for Psychiatric Research, Orangeburg, New York 10962, ${ }^{2}$ Behavioral and Cognitive Neuroscience \\ Program, City University of New York, New York, New York 10065, and ${ }^{3}$ Department of Child and Adolescent Psychiatry, New York University Langone \\ Medical School, New York, New York 10016
}

Odor perception is hypothesized to be an experience-dependent process involving the encoding of odor objects by distributed olfactory cortical ensembles. Olfactory cortical neurons coactivated by a specific pattern of odorant evoked input become linked through association fiber synaptic plasticity, creating a template of the familiar odor. In this way, experience and memory play an important role in odor perception and discrimination. In other systems, memory consolidation occurs partially via slow-wave sleep (SWS)-dependent replay of activity patterns originally evoked during waking. SWS is ideal for replay given hyporesponsive sensory systems, and thus reduced interference. Here, using artificial patterns of olfactory bulb stimulation in a fear conditioning procedure in the rat, we tested the effects of imposed post-training replay during SWS and waking on strength and precision of pattern memory. The results show that imposed replay during post-training SWS enhanced the subsequent strength of memory, whereas the identical replay during waking induced extinction. The magnitude of this enhancement was dependent on the timing of imposed replay relative to cortical sharp-waves. Imposed SWS replay of stimuli, which differed from the conditioned stimulus, did not affect conditioned stimulus memory strength but induced generalization of the fear memory to novel artificial patterns. Finally, post-training disruption of piriform cortex intracortical association fiber synapses, hypothesized to be critical for experience-dependent odor coding, also impaired subsequent memory precision but not strength. These results suggest that SWS replay in the olfactory cortex enhances memory consolidation, and that memory precision is dependent on the fidelity of that replay.

Key words: memory; odor memory; odor object; olfaction; piriform cortex; sleep

\section{Introduction}

Odor perception, similar to other senses, is experience dependent. Olfactory perceptual acuity can be improved or impaired through training (Rabin, 1988; Stevenson, 2001; Wilson and Stevenson, 2006; Li et al., 2008; Chen et al., 2011; Chapuis and Wilson, 2011). One locus for the neural events underlying olfactory perceptual learning is the piriform cortex (Li et al., 2008; Chen et al., 2011; Chapuis and Wilson, 2011). The piriform cortex is capable of learning patterns of odor-evoked afferent activity to form perceptual odor objects (Haberly, 2001; Isaacson, 2010; Wilson and Sullivan, 2011). Storing memories of familiar odorevoked patterns can promote both perceptual stability through pattern completion, and enhance odor discriminability between highly overlapping inputs (pattern separation; Sahay et al., 2011; Wilson and Sullivan, 2011).

Received Dec. 17, 2013; revised Feb. 26, 2014; accepted March 2, 2014.

Author contributions: D.C.B. and D.A.W. designed research; D.C.B. performed research; D.C.B. and D.A.W. analyzed data; D.C.B. and D.A.W. wrote the paper.

D.C.B. was funded by a predoctoral fellowship from NIDCD (F31-DC012284). D.A.W. was funded by grants from NIDCD (R01-DC03906 and R01-DC009910).

The authors declare no competing financial interests.

Correspondence should be addressed to either Dylan Barnes or Dr Donald Wilson, Emotional Brain Institute, Nathan Kline Institute for Psychiatric Research, 140 Old Orangeburg Road, Orangeburg, New York 10962, E-mail: donald.wilson@nyumc.org ordbarnes@gc.cuny.edu.

DOI:10.1523/JNEUROSCI.5274-13.2014

Copyright $\odot 2014$ the authors $\quad 0270-6474 / 14 / 345134-09 \$ 15.00 / 0$
Consolidation of such memories is sleep-dependent in many systems (Maquet, 2001; Stickgold and Walker, 2007; Diekelmann et al., 2009). Sleep-dependent consolidation has been linked to emotional, procedural, and declarative memory in human and nonhuman animals (Gais et al., 2000; Huber et al., 2004; Cai et al., 2009). Both REM and non-REM or slow-wave sleep (SWS) have been implicated in memory consolidation. SWS is characterized by slow oscillations $(1-5 \mathrm{~Hz})$ in widespread thalamic and neocortical neurons (Buzsáki, 1996; Steriade, 2006) and coincident sharp-wave ripples in both the hippocampal formation and piriform cortex (Mölle et al., 2006; Manabe et al., 2011). During SWS, sensory cortices are hyporesponsive to external stimuli (Murakami et al., 2005; Issa and Wang, 2011), thus consolidation can occur with limited interference from ongoing events.

One component of memory consolidation is replay, where the activity of neural ensembles that occurred during initial learning is repeated during post-training periods including SWS(Pavlides and Winson, 1989; Sutherland and McNaughton, 2000; Bendor and Wilson, 2012). Such replay is hypothesized to be critical for reinforcing synaptic changes induced by the initial learning (Lansink et al., 2009), transference of information across brain regions (Ji and Wilson, 2007), and homeostatic resetting of synaptic strength (Tononi, 2009). In the hippocampal formation spontaneous replay of information occurs during sharp-wave/ripples (Skaggs and McNaughton, 1996; Karlsson and Frank, 2009). Dis- 
ruption of hippocampal sharp-wave/ripple activity during posttraining sleep can impair memory consolidation (Ego-Stengel and Wilson, 2010), whereas enhancement of cortical slow-waves can enhance memory consolidation (Marshall et al., 2006). Furthermore, although sensory input is reduced during SWS, exposure during SWS to contextual cues associated with the learning event can enhance memory consolidation, perhaps by enhancing the effectiveness of replay (Rasch et al., 2007; Bendor and Wilson, 2012). In fact, exposure to conditioned stimuli during SWS may open the memory trace to manipulation, allowing the memory to be strengthened or weakened based on treatments given during sleep (Rolls et al., 2013).

The effectiveness of memory consolidation can be quantified in at least two ways; the strength of the stored representation and the accuracy or precision of the stored representation. For example, fear conditioning can result in varying degrees of subsequent fear to the conditioned stimulus (i.e., memory strength) and also varying degrees of generalization to similar stimuli (i.e., memory precision). It is unknown whether SWS-dependent replay affects both of these metrics. By using precise spatiotemporal patterns of olfactory bulb (OB) stimulation (Uchida et al., 2000; Johnson and Leon, 2007) as conditioned stimuli (CS), and then subsequently imposing replay of them during different behavioral stages and conditions, we were able to test the role of SWS replay in both the strength and accuracy of this form of pattern memory.

\section{Materials and Methods}

Subjects. Ninety male Long-Evans hooded rats $(250-450 \mathrm{~g})$ were used as subjects. Animals were housed individually in polypropylene cages on a $12 \mathrm{~h}$ light/dark cycle, with food and water available ad libitum.

\section{Electrical $O B$ stimulation}

Electrodes, surgery, and histology. Chronic recordings of sleep activity were performed with telemetry (Data Sciences International). Local field potential (LFP) recordings were obtained using a Teflon-coated 0.18$\mathrm{mm}$-diameter electrode chronically implanted in the anterior piriform cortex. Bilateral electrodes were also implanted in the nuchal muscles to record EMG. All recording electrodes were connected to a subdermal telemetry pack that was implanted above the animal's left shoulder. For implants, naive animals were surgically anesthetized with isoflurane. A recording electrode was implanted and cemented to the rat's skull, with the tip in the anterior piriform cortex (1.0 $\mathrm{mm}$ anterior to the bregma, 4.5 $\mathrm{mm}$ laterally, and $6 \mathrm{~mm}$ ventral to the surface of the brain). To condition animals in the electrical olfactomimetic stimulation-fear paradigm, rats had two or three Teflon-coated 0.18 -mm-diameter stainless steel stimulating electrodes implanted unilaterally into the mitral cell layer of one of the OBs (7.0 mm anterior to the bregma, $1-1.5 \mathrm{~mm}$ laterally, and $1-3 \mathrm{~mm}$ ventral to the surface of the brain), with at least $1 \mathrm{~mm}$ between electrodes(Mouly et al., 1985). Antibiotics and analgesics were intramuscularly injected in the rats immediately after the surgery. Animals were given 1 week for recovery before conditioning began. Following the end of behavioral testing, rats were given an overdose of urethane and then perfused intracardially with $0.9 \%$ saline followed by $10 \%$ formaldehyde. Brains removed from the skulls were stored in a $30 \%$ sucrose $10 \%$ formaldehyde solution for later sectioning. The brains were sectioned coronally at $40 \mu \mathrm{m}$, mounted on slides, and stained with cresyl violet. Electrode tracks and locations were verified under a light microscope and marked on a standard brain atlas plate.

Electrical $O B$ stimulation-foot shock conditioning. Training for animals in the electrical OB stimulation experiments $(n=46)$ began 1 week after surgery. A $3 \mathrm{~d}$ protocol was used. On Day 1, the rat was given a $30 \mathrm{~min}$ exposure to the training chamber with no stimuli delivered to allow habituation to the chamber context (a Plexiglas box, $27.5 \times 21 \times 20 \mathrm{~cm}$ with a shock grid floor), immediately followed by a $4 \mathrm{~h}$ period in a sound and light attenuated recording chamber $(30 \times 15 \times 17 \mathrm{~cm})$ to record spontaneous piriform cortex activity and monitor sleep/wake cycles. Output of the telemetry pack was sent to a Cambridge Electronic Design analog-to-digital converter, and acquired and analyzed with Spike2 software. LFP data were acquired at $10 \mathrm{kHz}$ and EMG data acquired at $1 \mathrm{kHz}$. The electrophysiological data were also continuously monitored online to allow identification of SWS bouts. SWS was visually determined based on the presence of $10 \mathrm{~s}$ or more of large amplitude LFP waves and reduced EMG activity.

On Day 2, the animals were randomly divided into paired and unpaired groups, which in turn had a number of subgroups. Before training, the intensity of olfactomimetic stimulation was adjusted for each $O B$ electrode in each rat to the lowest sufficient to evoke sniffing (mean \pm $\mathrm{SEM}=28.4 \pm 1.9 \mu \mathrm{A}$ ). Artifacts produced from the olfactomimetic stimulation in the LFP recordings precluded analysis of conditioned stimulus-evoked activity in the piriform cortex. The paired groups received five or seven (see text) olfactomimetic-shock pairings. Each paired trial consisted of an electrical OB stimulus composed of a series of $100 \mathrm{~Hz}$ bursts of four, $0.1 \mathrm{~ms}$ duration pulses with bursts delivered every $160 \mathrm{~ms}$ (burst occurring at $5 \mathrm{~Hz}$, i.e., theta burst stimulation (Larson et al., 1986), for a total of $2 \mathrm{~s}$ through one of the OB electrodes. The stimulus parameters were chosen to roughly match the temporal structure of mitral cell odor-evoked activity (Fletcher and Wilson, 2003), are known to reliably evoke synaptic plasticity within the olfactory system, and have previously been used as olfactomimetic stimuli (Roman et al., 1987; Wilson et al., 2004). This number of trials was sufficient to produce reliable fear conditioning, but was well below that required for asymptotic conditioning which allowed for post-training manipulations to enhance memory. This electrode served as the CS+ and thus was followed immediately by a $1 \mathrm{~s}$, $0.5 \mathrm{~mA}$ foot shock. A second, randomly assigned electrode served as the CS - electrical stimulus. The CS - was never followed by foot shock, and was repeated 25 times over the course of the $30 \mathrm{~min}$ training session. The unpaired control groups received 5 electrical-OB stimulus presentations through one $\mathrm{OB}$ electrode and 25 via another $\mathrm{OB}$ electrode, along with 5 noncontingent foot shocks over the course of the 30 min session. After the 30 min training session in the conditioning box, paired and unpaired animals were returned to the dark, sound-attenuated chamber and LFPs and EMG were recorded for $4 \mathrm{~h}$. During this $4 \mathrm{~h}$ postconditioning phase, most animals received imposed OB replay while in either SWS or awake states. These imposed replay stimuli were pseudorandomly dispersed across the $4 \mathrm{~h}$ period, dependent on the behavioral state. Stimulations were given randomly over $4 \mathrm{~h}$ with $\sim 10$ given in the first $2 \mathrm{~h}$ (SWS = $9.9 \pm 1.1$; awake $=12.1 \pm 1.5)$ and 10 given in the second $2 \mathrm{~h}$ (SWS $=$ $11.3 \pm 1$; awake $=7.8 \pm 1.5$ ). Paired and unpaired animals were randomly divided into three groups based on treatment received during the $4 \mathrm{~h}$ post-training period. They either received no electrical stimulation $(n=4)$, or received CS + electrical-stimulus stimulation (20 repeats) either while the animal was awake $(n=6)$, or in SWS $(n=6)$. In a separate experiment, additional paired and unpaired animals were trained as described but received during SWS post-training electrical stimulation via a third, previously unused $\mathrm{OB}$ electrode that was neither the CS + or CS - (MisMatch). Following the $4 \mathrm{~h}$ post-training period, all animals were returned to their home cages until the next day when they were tested. Finally, in additional paired animals, imposed replay was delivered timed to sharp-wave events recorded in the piriform cortex. Animals were trained with $2 \mathrm{~s}$ electrical OB stimuli paired with footshock as described above. During post-training SWS, CS + OB stimuli $(50 \mathrm{~ms}$ duration, $100 \mathrm{~Hz}$ trains, 40 repeats) were given with onset either at the peak of a sharp-wave $(n=3)$ or $200 \mathrm{~ms}$ after the peak of a sharp-wave $(n=3)$, or animals received no post-training stimulation $(n=3)$.

On Day 3, 24 h post-training, animals were placed in a different context and given three presentations ( 5 min between stimuli) of the CS+, the CS - , and the MisMatch (if appropriate) stimuli. Behavioral (freezing; Fanselow and Gale, 2003) responses to the stimuli were quantified over a $30 \mathrm{~s}$ period beginning with stimulus onset of $2 \mathrm{~s}$ duration. Freezing was measured by quantifying continuous immobility in response to the $2 \mathrm{~s}$ stimulus and ceased after the animal began moving, or until the end of the $30 \mathrm{~s}$ observation period.

\section{Pharmacology methods}

Acute physiology. Six animals were anesthetized with urethane $(1.25 \mathrm{~g} / \mathrm{kg})$ and placed in a stereotaxic apparatus. Holes were drilled into the skull 
over the lateral olfactory tract (LOT), anterior piriform cortex, and posterior piriform cortex ( $\mathrm{pPCX}$ ). Stimulating electrodes were placed in the LOT ( $4 \mathrm{~mm}$ lateral, $3 \mathrm{~mm}$ anterior to bregma) and layer III of the pPCX ( $6 \mathrm{~mm}$ lateral, $3 \mathrm{~mm}$ posterior to bregma). LFP recordings were obtained using a Teflon-coated 0.18 -mm-diameter electrode in layer I of the anterior piriform cortex ( $4 \mathrm{~mm}$ lateral, $1 \mathrm{~mm}$ anterior to bregma). The intensity of stimulation was calibrated for each electrode and each animal to provide a response magnitude of $\sim 50 \%$ of maximum, and ranged between 90 and $300 \mu \mathrm{A}$. A 0.2-mm-diameter cannula was also lowered into aPCX near the tip of the recording electrode. Alternating stimulation to the LOT (afferent input) and pPCX (association fiber input) was maintained every $10 \mathrm{~s}$ for the remainder of the recording session. Following stabilization of the evoked synaptic responses, data collection began with a $10 \mathrm{~min}$ baseline period. This was followed by $2 \mu \mathrm{l}$ of either the $\mathrm{GABA}_{\mathrm{B}}$ receptor agonist baclofen (concentration $500 \mu \mathrm{M}$ ) or saline was injected over a period of $10 \mathrm{~min}$. Following injection, a $20 \mathrm{~min}$ period of continued stimulation to LOT and pPCX was maintained. After the final recording, rats were given an overdose of urethane and then perfused intracardially with $0.9 \%$ saline followed by $10 \%$ formaldehyde. Brains removed from the skulls were stored in a $30 \%$ sucrose $/ 10 \%$ formaldehyde solution for later sectioning. The brains were sectioned coronally at $40 \mu \mathrm{m}$, mounted on slides, and stained with cresyl violet. Electrode and cannula tracks and locations were verified under a light microscope and marked on a standard brain atlas plate.

Data analysis. Evoked potentials were quantified by calculating the onset slope of both LOT and PPCX evoked responses across the entire recording period. A repeated-measures ANOVA was used to determine the effects of baclofen infusion on the responses.

Chronic physiology. LFP recordings were obtained using a Tefloncoated $0.18-\mathrm{mm}$-diameter electrode chronically implanted in the anterior piriform cortex $(n=20)$ as described above, with the exception that no stimulating electrodes were implanted in the OBs. Bilateral electrodes were also implanted in the nuchal muscles to record EMG. All recording electrodes were connected to a subdermal telemetry pack that was implanted above the animal's left shoulder. In addition, guide cannula's ( $0.2 \mathrm{~mm}$ diameter, 26 gauge) were implanted bilaterally into the anterior piriform cortex. Antibiotics and analgesics were intramuscularly injected in the rats immediately after the surgery and animals were given 1 week for recovery.

Natural odor shock conditioning. One week after surgery, animals were trained in the $3 \mathrm{~d}$ conditioning session as described above for electrical odors, with the exception that natural odors were used here. On Day 1, the animals were placed in conditioning box (as described above) with a shock grid floor for $30 \mathrm{~min}$ with no odor or footshock stimuli, and then placed in the recording chamber (as described above) for $4 \mathrm{~h}$. On Day 2, the animals were randomly divided into 4 groups; paired-saline; pairedbaclofen; unpaired-saline and unpaired-baclofen. Paired animals received seven CS + natural odor-shock pairings randomly mixed with 25 CS - natural odor presentations. Unpaired animals had seven CS + and $25 \mathrm{CS}$ - randomly mixed presentations along with seven unpaired 0.5 $\mathrm{mA}$ foot shocks. For this experiment, we used $5 \mathrm{~s}$ pulses of a 10component odor mixture odor for the CS + and for the CS - we used a 10 -component odor mixture that overlapped with the CS + by $90 \%$ with one of the original components replaced by a novel component (10cR1; see below for further details of the mixtures). After the 30 min conditioning session, cannulas were attached to a syringe infusion pump with PE60 tubing, and the cannulas inserted into the previously implanted guide cannulas. The animals were then placed in the dark sound-attenuated chamber and LFPs and EMG were recorded for $4 \mathrm{~h}$. At the onset of this $4 \mathrm{~h}$ postconditioning phase, animals received $4 \mu \mathrm{l}$ of either $500 \mu \mathrm{M}$ baclofen or sterile saline $(0.1 \mu \mathrm{l} / \mathrm{min})$ in the anterior piriform cortex. Following recording, the animals were disconnected from the tubing and then returned to their home cages until testing the next day. On Day 3, the rats were placed in a different context and given three presentations of both the CS+ and CS - odors (stimulus duration $5 \mathrm{~s}$ ) along with three presentations of three other similar odors. Behavioral responses (freezing) to the conditioned odors were quantified as above.

Sleep-state data analysis. LFP and EMG data were collected and analyzed off-line using Spike 2 (CED). Fast Fourier Transform (FFT) power analyses were done on the raw LFP data in $14 \mathrm{~s}$ intervals to obtain measures of power in $2.4 \mathrm{~Hz}$ frequency bins from 0 to $100 \mathrm{~Hz}$. Power in both the delta $(0-5 \mathrm{~Hz})$ and theta $(5-10 \mathrm{~Hz})$ frequency bands were calculated for each 14 second window. To qualify as SWS, an individual $14 \mathrm{~s} \mathrm{time}$ period had to have an LFP delta value that was higher than the overall delta value for the whole time series and a theta/delta ratio that was $<0.9$ (Costa-Miserachs et al., 2003). LFP data were also filtered and analyzed to examine sharp wave amplitude during baseline recording day, immediately after training, and $24 \mathrm{~h}$ post training.

Odor mixtures. The odor mixture set used in this project is the same as used by Barnes et al. (2008), Chapuis and Wilson (2011), Chen et al. (2011), and Lovitz et al. (2012). These mixtures have been well characterized using both sensory physiology and psychophysical techniques, and have been shown to differ dramatically in their overall qualities. Mixtures were created by adding odorant components to mineral oil in amounts that provided component concentrations (100 ppm for all components except 1,7-octadiene which was at $400 \mathrm{ppm}$ ) within the mixture on the basis of individual odorant vapor pressure(Barnes et al., 2008). The CS + 10-component mixture (10c) included the following monomolecular odorants (vapor pressure in $\mathrm{mmHg}$ indicated in parentheses): isoamyl acetate (5.00), nonane (4.29), ethyl valerate (4.80), 5-methyl-2-hexanone (4.60), isopropylbenzene (4.58), 1-pentanol (6.11), 1,7-octadiene (22.1), 2-heptanone (3.86), heptanal (3.52) and 4-methyl-3-penten-2-one (6.69). The CS- was transformed by the replacement of one component (isoamyl acetate) by another component (limonene, $1.98 ; 10 \mathrm{cR} 1$ ). Novel test odors were created by modifying the 10c mixture by the removal of one (isoamyl acetate) or two (isoamyl acetate and nonane) components (10c-1, 10c-2) or presenting limonene alone. During the test phase, the rat's ability to discriminate the 10c core mixture from its related sets was evaluated by evoked freezing behavior.

\section{Results}

Freely moving rats were trained in a standard odor-shock fear conditioning paradigm, with natural odors replaced by electrical stimulation of different spatial locations in the OB (Mouly et al., 1985). Electrical, olfactomimetic stimulation of the OB and LOT produces similar behavioral and physiological responses as natural odors (Roman et al., 1987; Kumar et al., 2012). Animals sniff in response to the electrical OB stimulus (Fig. $1 B$ ), and can learn to differentially freeze in response to an olfactomimetic electric stimulus (CS+) that signals footshock and not freeze to an electrical stimulus (CS-) not paired with foot shock (Fig. 2A) when tested in a novel context the following day. It should be noted that fear conditioning paradigms using natural odors generally involve 10-20 s CS presentations during training and $20 \mathrm{~s}$ or longer CS presentations during testing to assess freezing (Funk and Amir, 2000; Hegoburu et al., 2009; Pavesi et al., 2012; Kass et al., 2013; Roth et al., 2013; Dias and Ressler, 2014). The electrical, olfactomimetic stimuli used here precluded the use of such extended stimuli, yet were sufficient to evoke freezing responses often extending long after the 2 s olfactomimetic stimulus.

\section{Imposed replay during post-training SWS enhances memory consolidation, whereas the same replay during waking induces extinction}

Rats were trained in the electrical olfactomimetic fear conditioning paradigm ( 5 pairings of CS + and footshock, 25 presentations of CS-), or were pseudotrained, and then allowed to rest in a darkened, quiet chamber for $4 \mathrm{~h}$ immediately following the termination of training (Fig. 1A). The number of conditioning trials was chosen to be sufficient to produce reliable fear conditioning, but be well below that required for asymptotic conditioning to allow for post-training SWS-related memory enhancement to be detected. During the $4 \mathrm{~h}$ post-training period, LFP's were recorded from the anterior piriform cortex, and EMG's from the 
A
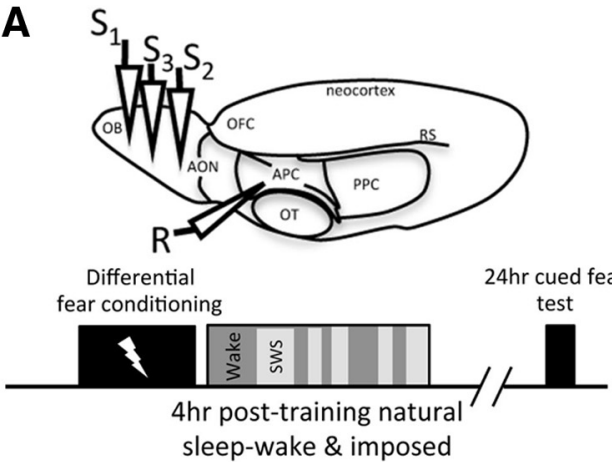

replay
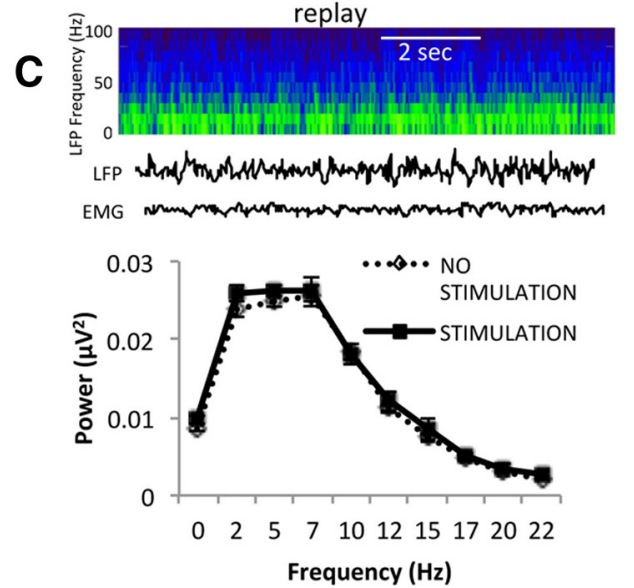

B
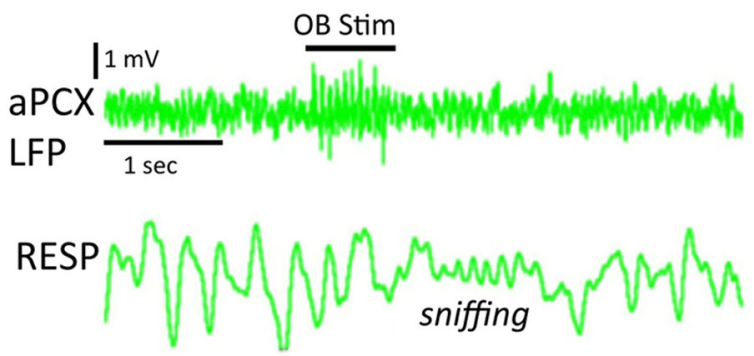
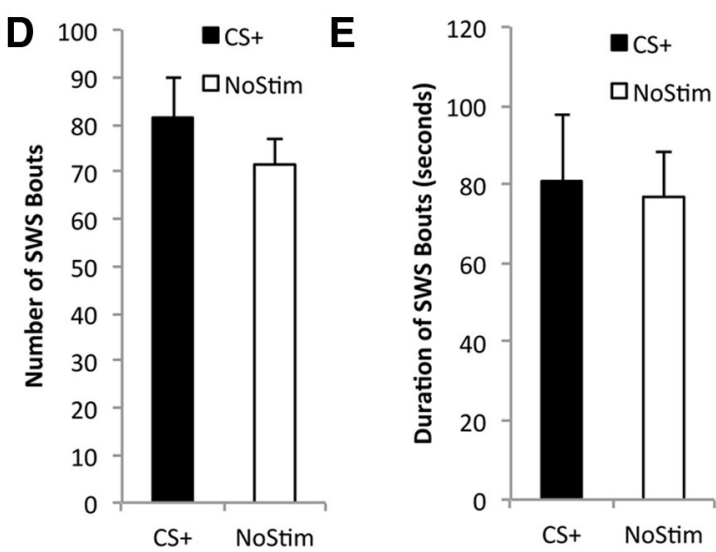

Figure 1. $\quad A$, The basic experimental paradigm for electrical $O B$ stimulation and conditioning. Animals were implanted with three stimulating electrodes in the $O B$ and a recording electrode in aPCX. During conditioning, stimulation of one of the $0 B$ electrodes was randomly chosen to be paired with a $0.5 \mathrm{~mA}$ foot shock (CS+) whereas stimulation of another was not paired (CS - ). During the $4 \mathrm{~h}$ post-training period, the $C S+$ or a novel stimulus, the MisMatch electrode (MM), was given at least 20 times during natural bouts of slow-wave activityor during waking. $24 \mathrm{~h}$ later, the animal was placed in a new context and given three presentations of the $C S+$, the $C S-$, and MM to test for stimulus evoked freezing. $B$, A representative example of theLFP recorded in the aPCX and respiratory (Resp) response to a brief olfactomimetic OB stimulus. C, Top, A representative pseudocolor sonogram, LFP trace, and EMG trace from one animal during imposed replay (white line) while in SWS. Presenting an electrical OB stimulus during SWS did not waken animals. Bottom, A representative comparison of FFT power spectra for SWS during OB stimulation showing no difference in slow-wave power structure. $\boldsymbol{D}$, The number of SWS bouts over the $4 \mathrm{~h}$ post-training period for animals that received OB stimulus presentation during SWS ( $n=9$ ) and animals that received no imposed replay $(n=8)$. There was not a significant difference between groups. $E$, The mean duration of SWS bouts post-training for animals that received OB stimulation was not significantly different from the mean duration of SWS bouts for animals that received no stimulation.

nuchal muscle to determine sleep/waking cycles. A subset $(n=6)$ of the paired animals received electrical OB stimulation that matched the CS+ pattern selectively during post-training SWS. This imposed SWS replay was repeated 20 times throughout the $4 \mathrm{~h}$ period. Stimulation was not temporally locked to specific phases of piriform cortical sharp-waves. Presenting electrical OB stimulation during sleep did not significantly change the number or mean duration of SWS bouts compared with no stimulation groups (number of bouts $t_{(8)}=0.815, p>0.1$; Fig. $1 D$ ); duration of bouts $t_{(8)}=0.173, p>0.5$; Fig. $\left.1 E\right)$. Furthermore, FFT analysis of LFP oscillations during SWS showed no difference between bouts paired with stimulation and those without stimulation (Fig. 1C). An additional group of animals was tested with REM imposed replay; however, these animals consistently awoke to the electrical odor and thus are not included here. Animals receiving the imposed SWS replay demonstrated enhanced freezing to the $\mathrm{CS}+$ stimulus $24 \mathrm{~h}$ following conditioning (Fig. $2 \mathrm{~A}$ ) compared with animals in the paired group that received no post-training stimulation $(n=6)$. A second subset $(n=6)$ of paired group animals received post-training CS + stimulation selectively during waking bouts in the $4 \mathrm{~h}$ post-training period. This imposed waking replay reduced CS + evoked freezing, consistent with extinction, though this effect was small. All paired animals showed freezing selectively to the CS + and not to the CS - . The pseudoconditioned animals $(n=5)$ did not show any significant freez- ing to either stimulus. There was a significant group $\times$ stimulus interaction $\left(F_{(5,20)}=4.88, p=0.006\right)$, and post hoc tests revealed that paired:no stimulation and paired SWS stimulation froze significantly more to the CS + than CS - and compared with control groups (Fisher's PLSD $p<0.05$ ). Furthermore, paired animals with $\mathrm{CS}+$ presentation during SWS froze significantly more to the CS+ compared with all other groups (Fisher's PLSD $p<0.05$ ).

To test whether the limited extinction effects in the paired-awake animals was due to a floor effect, we increased the number of $\mathrm{CS}+/ \mathrm{US}$ pairings during conditioning to seven (Fig. $2 B$ ). With this additional training, paired: awake $\mathrm{CS}+$ animals showed significantly reduced CS + evoked freezing compared with the paired, no stimulation group $\left(F_{(1,10)}=8.09, p=0.0174\right)$. Thus, imposed replay of the $\mathrm{CS}+$ during SWS enhanced memory of the CS+, whereas the identical replay during waking induced extinction.

Finally, to test whether the timing of imposed replay relative to the piriform cortical sharp-waves influenced consolidation and additional group of paired animals, received post-training $\mathrm{CS}+$ stimulation selectively beginning at the peak of sharp-waves $(n=3)$ or $200 \mathrm{~ms}$ after sharp-wave peak $(n=3)$, or received no post-training stimulation $(n=3)$. The $200 \mathrm{~ms}$ time point was chosen to be well after the termination of a sharp-wave and yet not likely to near a subsequent sharp-wave (Fig. 2D). In this case, the imposed replay stimulus was reduced to $50 \mathrm{~ms}$ in duration $(100 \mathrm{~Hz}, 40$ repeats over the $4 \mathrm{~h}$ post-training period). Neither the 
A
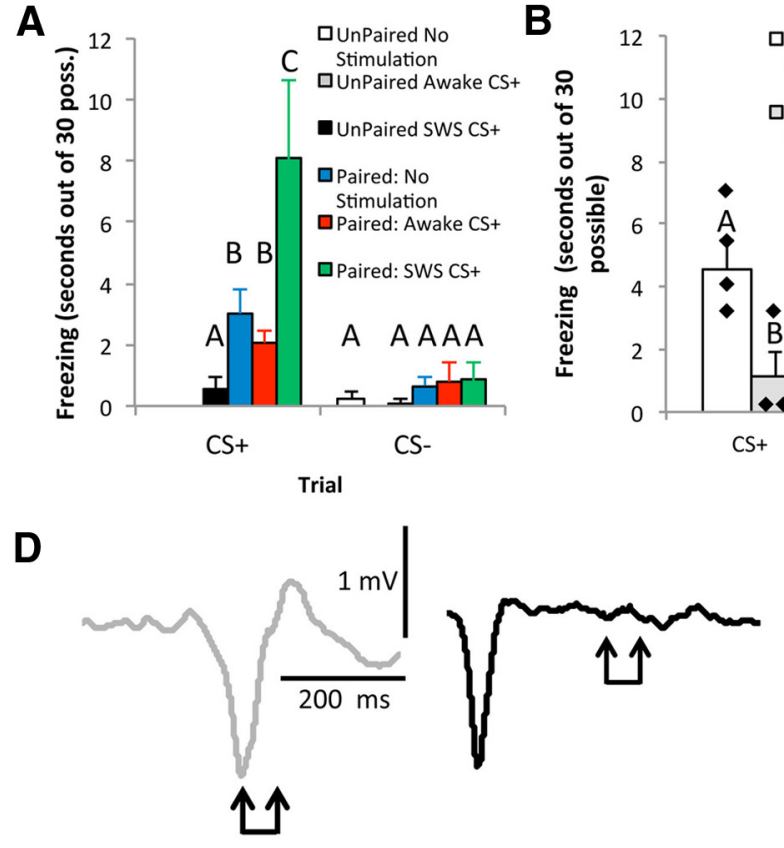

B

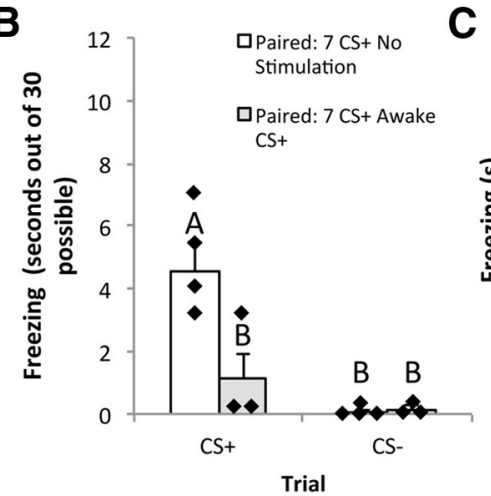

Paired SWS CS+

- Paired SWS MM

口UnPaired SWS MM

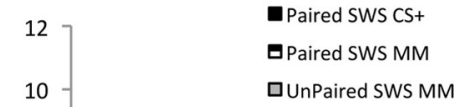

E

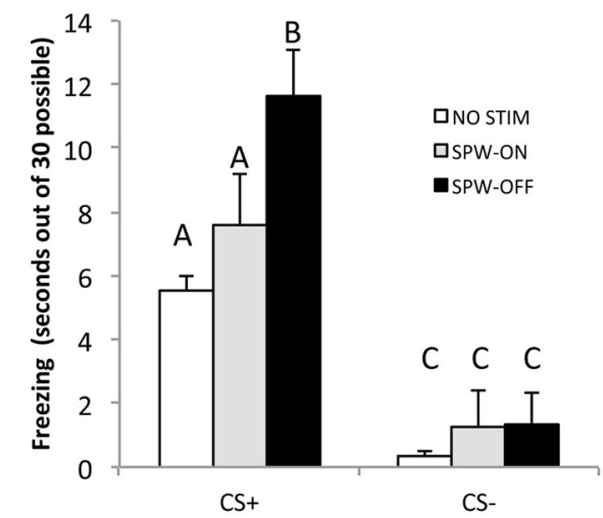

Figure 2. A, Following differential electrical OB stimulation aversion conditioning, paired animals that had $C S+$ matching pattern reinforcement during post-training SWS $(n=6)$ showed enhanced freezing to the $C S+$ stimulus compared with animals in the paired group that received no post-training stimulation $(n=4)$. Animals in the paired group that received post-training $C S+$ stimulation during waking $(n=6)$ showed reduced freezing, consistent with extinction. All paired animals showed freezing selectively to the $C S+$ and not to the $C S-$. None of the unpaired conditioning groups showed any significant freezing response to either stimulus presented $24 \mathrm{~h}$ following pseudoconditioning. In this and subsequent figures, groups with the same alphabetic label are not significantly different from each other based on post hoc tests. Groups with different alphabetic labels are significantly different from each other based on post hoc tests $(p<0.05)$. $\boldsymbol{B}$, To eliminate the floor effect between paired: no stimulation and paired: Awake groups, we increased the number of CS+/US pairings during conditioning to 7 . With this additional training, paired awake $C S+$ animals $(n=3)$ showed significant extinction compared with the no stimulation group $(n=3)$. Data points from all individual animals are included to represent typical intersubject variation in this and all behavioral experiments. C, Following the presentation of a novel stimulus that did not match the $C S+$ during post-training SWS, paired animals that received mismatching pattern stimulation during the SWS $(n=4)$ showed generalized freezing on the test day. Paired animals that had $(S+$ matching pattern replay during SWS $(n=5)$, however, showed selective freezing to only the $C S+$. Unpaired animals $(n=4)$ showed no evoked freezing response on the test day. $\boldsymbol{D}$, To examine the effects of $C S+$ imposed replay timing relative to piriform cortical sharp-waves, we presented the imposed $(S+$ either during the sharp-wave peak or $200 \mathrm{~ms}$ after the sharp-wave peak. Arrows mark onset and offset of stimulation. $\boldsymbol{E}$, Animals receiving imposed $C S+$ replay $200 \mathrm{~ms}$ after sharp-waves $(n=3)$ showed enhanced freezing response on the test day compared with the no stimulation $(n=3)$ and the on-peak stimulation ( $n=3)$ groups). The A-marked group represents significant selective freezing to the CS + compared with CS - . The B-marked group signifies animals with delayed imposed replay froze significantly more than all other groups.

presence nor timing of stimulation affected the frequency or number of sharp waves during the post-training period; $F_{(2,6)}=$ $0.676, p=0.53$. Animals receiving the imposed SWS replay 200 $\mathrm{ms}$ after sharp-waves demonstrated enhanced freezing to the CS+ following conditioning (Fig. 2E) compared with animals that either received either no post-training stimulation or imposed replay during sharp-waves $\left(F_{(2,6)}=5.36, p=0.044\right)$. Post hoc tests showed animals that received imposed replay on the peak of sharp-waves did not freeze significantly more than animals that received no post-training stimulation, while the $200 \mathrm{~ms}$ delayed imposed replay animals showed significantly more freezing than the no stimulation group (Fisher's PLSD $p=0.018$ ).

\section{Imposed interference during post-training SWS impairs the precision of memory consolidation}

Animals were differentially conditioned with electrical OB stimulation and footshock as described above, or were pseudoconditioned. During the $4 \mathrm{~h}$ postconditioning period, animals received either imposed SWS replay that matched the CS+, or received imposed "replay" of a novel electrical stimulus pattern (third electrode) to which they had not been previously exposed. As above, paired animals that received imposed SWS replay of the $\mathrm{CS}+$ showed selective freezing to the CS $+24 \mathrm{~h}$ following conditioning (Fig. 2C). Paired animals that received imposed "replay" of the novel electrical stimulus, however, showed normal freezing to the CS+, which was not stimulus selective. These animals displayed generalized freezing on the test day to the CS+, the CS - , and the mismatching stimulation. Unpaired animals showed no evoked freezing on the test day. There was a significant main effect of stimulus $\left(F_{(2,10)}=10.15, p=0.0009\right)$ and a significant main effect of group $\left(F_{(2,10)}=6.22, p=0.0176\right)$. Post hoc tests revealed paired animals with the mismatched stimulus presented during SWS froze significantly more to all electrical odor stimuli compared with the other groups (Fisher's PLSD $p=0.0366$ ). Thus, imposed interfering novel input patterns during natural SWS replay can impair the accuracy of the consolidated memory.

Blockade of piriform cortex intracortical association fiber synapses during post-training consolidation impairs the precision of odor memory

Piriform cortical odor coding necessary for fine odor discrimination is dependent on plasticity at intracortical association fiber 
A
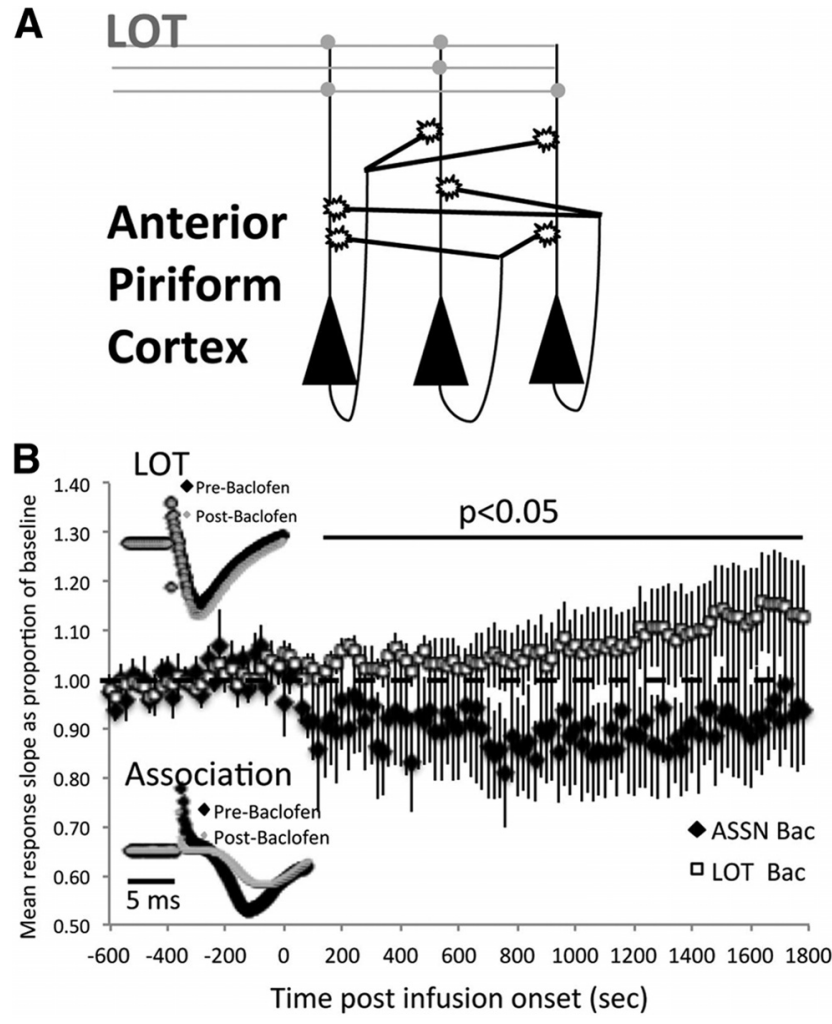

Figure 3. $A$, Schematic diagram of aPCX circuitry including afferent (LOT) and association fibers. Baclofen selectively depresses the association fiber synapses (stars). $\boldsymbol{B}$, Baclofen infused into the anterior piriform cortex selectively depressed intracortical association fiber synaptic responses while having no effect on afferent fiber evoked (LOT) synaptic responses. The bar represents a significant difference in LOT and association fiber evoked responses. Inset, Examples of LOT- and association fiber-evoked responses before and after baclofen infusion.

synapses (Hasselmo and Barkai, 1995; Linster et al., 2009). It has been hypothesized that distributed, coactive piriform cortical neurons (Fig. $3 A$ ) can become bound through enhancements in synaptic strength of these association synapses (Johnson et al., 2000; Wilson and Sullivan, 2011). During SWS, association fiber synapses are released from cholinergic suppression and may come to be the predominate driver of cortical activity (Barkai and Hasselmo, 1997; Hasselmo and McGaughy, 2004). Thus, the olfactomimetic stimulation during post-training SWS may act in part to bind cortical ensembles active during the replay, via intracortical association fiber synapse plasticity. Here we tested the role of association fiber synapses in post-training memory consolidation, with the hypothesis that selective suppression of these synapses would impair SWS replay and memory accuracy. We used infusions of the $\mathrm{GABA}_{\mathrm{B}}$ agonist baclofen directly into the piriform cortex during the post-training consolidation period to test whether association fiber synaptic activity modulates posttraining odor memory consolidation. If an effect is observed, the experiment also helps localize post-training consolidation mechanism to the piriform cortex itself. Finally, to test the generality of the post-training memory consolidation effects observed above with olfactomimetic stimulation, we used chemical odorants as the conditioning stimuli.

Piriform cortical association fiber evoked synaptic responses are selectively reduced after local baclofen infusion

It has previously been reported in in vitro preparations (Patil and Hasselmo, 1999) and in vivo animals with the piriform cortex surface surgically exposed (Poo and Isaacson, 2011) that the
$\mathrm{GABA}_{\mathrm{B}}$ receptor agonist baclofen selectively suppresses association fiber synapses in the piriform cortex, with minimal effects on $\mathrm{OB}$ afferents to the piriform cortex. Similarly here in intact animals with indwelling cannula aimed at the anterior piriform cortex we demonstrate that local infusion of $2 \mu \mathrm{l}$ of $(500 \mu \mathrm{M})$ baclofen significantly depressed synaptic responses evoked by association fiber stimulation, but had no significant effect on afferent fiber evoked synaptic responses (repeated-measures ANOVA $F_{(119,1190)}=1.39, p=0.0046$; Fig. $\left.3 B\right)$.

\section{Baclofen suppresses SWS associated sharp wave amplitude}

Current source density analyses suggest an important role for intracortical association fiber synapses in SWS related sharp waves in piriform cortex (Manabe et al., 2011). To test whether baclofen had an effect on piriform cortical sharp wave activity, we analyzed average sharp wave amplitude during bouts of posttraining SWS in chronically implanted animals. Bilateral intrapiriform cortex baclofen infusion did not significantly change the amount of time animals spent in post-training SWS (Fig. 4A; nonsignificant conditioning $\times$ drug interaction; $F_{(1,15)}=0.05$, $p=0.817$ ). As we have previously reported (Barnes et al., 2011), animals that underwent paired conditioning spent significantly more time in post-training SWS during the $4 \mathrm{~h}$ immediately posttraining than pseudoconditioned animals (main effect of conditioning; $\left.F_{(1,15)}=8.89, p=0.0093\right)$. However, although the time spent in SWS was not affected by piriform cortex baclofen (Fig. $4 C$ ), sharp-wave amplitude was significantly decreased in baclofen infused paired animals (Fig. $4 B$; ANOVA, group $\times$ drug interaction; $F_{(1,14)}=5.08, p=0.042$ ). Thus, baclofen infusion reduces association fiber synapse efficacy and the amplitude of SWS associated sharp waves in piriform cortex.

Post-training baclofen in piriform cortex impairs accuracy of odormemory consolidation, but not memory strength

To assess how depression of intracortical association fiber synapses in piriform cortex affects post-training memory consolidation, we differentially conditioned animals using natural odors, administered bilateral intrapiriform cortical baclofen immediately after conditioning, and then tested each animal for an odorevoked fear response $24 \mathrm{~h}$ after conditioning. The odors used include overlapping complex mixtures composed to 8-10 components that varied in number and identity, and that have been previously well characterized psychophysically (Barnes et al., 2008; Chapuis and Wilson, 2011). Given the nature of the pharmacological intervention, we were unable to suppress association synapses selectively during post-training SWS. After Paired differential odor-fear conditioning, animals that received control saline infusions during the post-training period froze selectively to the CS+ odor $24 \mathrm{~h}$ after conditioning. Paired animals who received baclofen infusions post-training, however, showed a generalized fear response to all odors during the test period (Fig. $4 D$ ). Both groups of unpaired animals showed no significant fear response to any stimulus presented $24 \mathrm{~h}$ following pseudoconditioning. There was a significant conditioning $\times$ drug interaction $\left(F_{(3,12)}=3.069, p=0.002\right)$. Post hoc tests revealed paired animals receiving baclofen post-training froze significantly more to all test odors compared with all other groups (Fisher's PLSD $p<0.001$ ). Thus, similar to the effects of imposed interference during post-training SWS consolidation, post-training depression of intrapiriform cortical association fiber synapses and sharp-wave amplitude impaired the selectivity of the consolidated odor memory. 
A

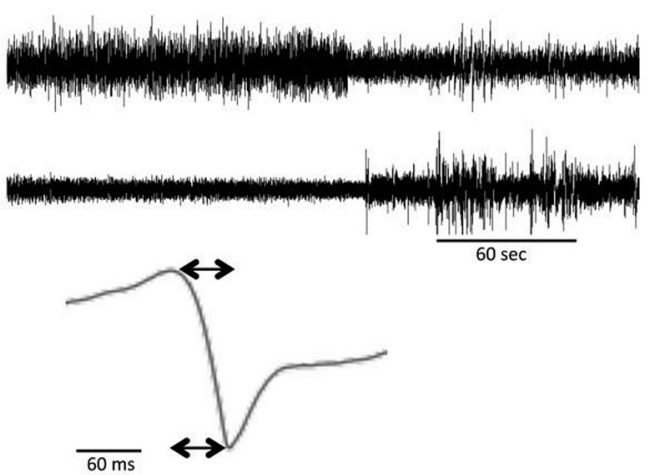

C

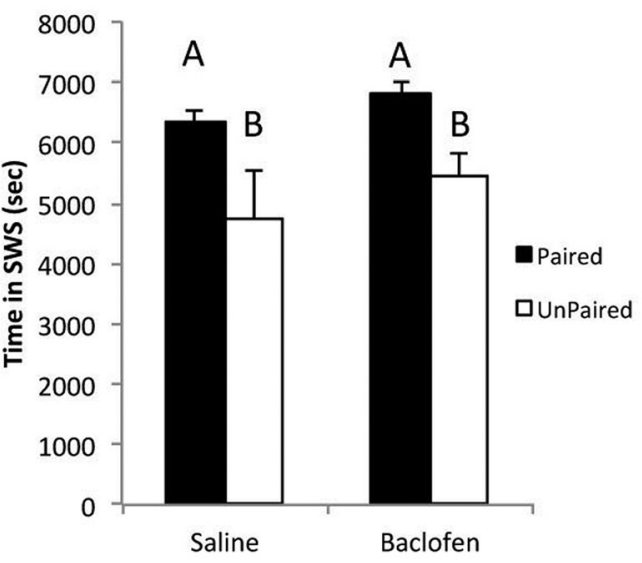

B

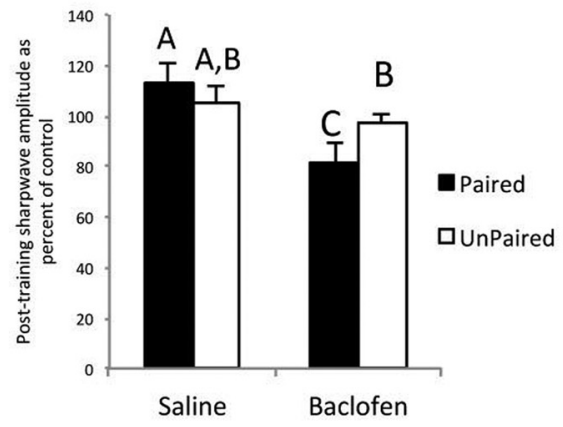

D

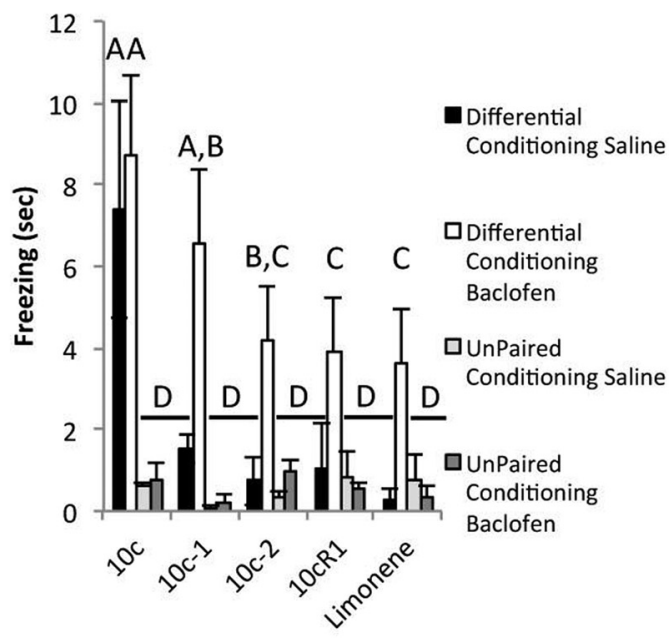

Figure 4. A, Top, A representative example showing a transition from SWS into waking as recorded in the aPCX. SWS is characterized by high delta power activity and relatively low EMG activity. Below is an example of an aPCX sharp-wave and its amplitude measurement. $\boldsymbol{B}$, Baclofen ( $n=9$; B-marked groups) reduced anterior piriform cortex sharp-wave amplitude compared with saline controls ( $n=9$; A-marked groups). This effect was greatest in animals trained in the paired baclofen condition ( $n=5$; Group C). C, Paired animals ( $n=10$; A-marked groups) spent significantly more time in SWS post-training than unpaired animals ( $n=10$; B-marked groups). Baclofen infusion into the anterior piriform cortex had no effect on the total time spent in SWS in either group (Fisher's PLSD $p<0.05$ ). D, Bilateral baclofen infusions into the anterior piriform cortex following training significantly enhanced generalization of odor-evoked freezing, without impacting freezing to the $\mathrm{CS}+$. Groups ( $n=5$ /group) with the same alphabetic label are not significantly different from each other based on post hoc tests. Groups with different alphabetic labels are significantly different from each other based on post hoc tests, $p<0.05$.

\section{Discussion}

Imposed replay of neural activity patterns during SWS, which were originally acquired during awake conditioning, enhanced the strength of memory for those patterns. Identical replay during waking, however, induced memory extinction. The replay of memories during SWS may be advantageous as sensory systems, including the olfactory system (Murakami et al., 2005; Wilson, 2010), are normally hyporesponsive in this state, allowing replay to occur in the absence of interference from external events. In fact, as demonstrated here, imposition of interfering patterns during natural SWS replay impaired the accuracy of the consolidated memory. In our case, this was displayed as a substantial increase in the generalization of stimulus-evoked fear. That is, the memory for the original CS+ was intact, but lacked precision. Importantly, the precision of memory for both olfactomimetic and natural odors was influenced by post-training consolidation. Given the nature of odor coding in the piriform cortex (Suzuki and Bekkers, 2006; Isaacson, 2010; Wilson and Sullivan, 2011), this result is consistent with the hypothesis that neurons coactivated by the CS + reinforce their coconnections by activity during SWS-associated sharp waves (Hasselmo and McGaughy, 2004; Wilson, 2010). Strengthening the connectivity of the coactive neurons via use-dependent, NMDA-dependent synaptic plasticity (Kapur and Haberly, 1998), enhances the precision of the cortically encoded odor object and its distinctiveness from other odors (Linster et al., 2009). In further support of the role of association fibers in SWS associated replay, selective suppression of association synapses during the post-training period (during both sleeping and waking) also impaired the precision of the consolidated memory, resulting in a false odor fear memory. Future work limiting the association fiber manipulation to either SWS or waking will be required to more fully characterize this feature of consolidation accuracy.

The timing of imposed replay during SWS had a significant effect on memory consolidation. The most effective treatment was not during the piriform cortical sharp-wave itself. Stimulating at a time other than during sharp-waves may have served as additional replay opportunities that enhanced consolidation. In addition, intense stimulation during the sharp-wave may have interfered with natural replay, an affect also observed in the hippocampus (Girardeau et al., 2009), though no impairment in memory was observed in our data compared with nonstimulated controls. Further work is required to assess this mechanism and more closely define the temporal window of effects.

It is also unknown why imposed replay during SWS enhances memory and the identical stimulation during waking induces extinction (Diekelmann et al., 2011). Access of odor input to circuits mediating fear extinction, such as amygdala and prefrontal cortex (Gottfried and Dolan, 2004; Sotres-Bayon et al., 2006; Myers and Davis, 2007; Maren, 2011) may be depressed during 
SWS, although extinction to contextual cues can occur during SWS (Hauner et al., 2013), and consolidation of extinction learning itself is sleep-dependent (Datta and O'Malley, 2013). Piriform cortical neuromodulatory tone and function is dramatically different during waking and SWS, which may reduce the ability of waking replay to facilitate odor memory. For example, acetylcholine suppresses association fiber synaptic efficacy through a reduction in presynaptic glutamate release, with minimal effect on afferent fiber synapses from mitral cells (Barkai and Hasselmo, 1997; Linster et al., 2003). As ACh levels drop during SWS, association fiber synapses are released from this suppression and can come to dominate PCX cortical activity. This shift in balance may contribute to sharp wave activity and single-cell bursting, which is an optimal firing pattern to strengthen synapses via LTP and Hebbian-like mechanisms. Thus, replay of afferent input during these two very different states may be likely to have different consequences for synaptic plasticity and memory.

These results extend the extensive replay and sleep-dependent consolidation literature of the hippocampal formation to the evolutionarily older piriform cortex and a nonhippocampaldependent memory. Both structures share remarkable similarities in structure and function, and now appear to share important similarities in sleep-related memory functions. The results also extend sleep related memory consolidation effects beyond simple memory strength to the accuracy of the stored information. Strong memories are not necessarily precise, and these two features can be differentially modulated during SWS.

Finally, these results further emphasize the importance of experience in shaping olfactory processing and odor perception (Wilson and Stevenson, 2006; Li et al., 2008; Chen et al., 2011; Chapuis and Wilson, 2011). It is now apparent that odor perception not only depends on the odors we smell, but also on memory reactivation of those odors during sleep.

\section{References}

Barkai E, Hasselmo MH (1997) Acetylcholine and associative memory in the piriform cortex. Mol Neurobiol 15:17-29. CrossRef Medline

Barnes DC, Hofacer RD, Zaman AR, Rennaker RL, Wilson DA (2008) Olfactory perceptual stability and discrimination. Nat Neurosci 11:13781380. CrossRef Medline

Barnes DC, Chapuis J, Chaudhury D, Wilson DA (2011) Odor fear conditioning modifies piriform cortex local field potentials both during conditioning and during post-conditioning sleep. PloS one 6:e18130. CrossRef Medline

Bendor D, Wilson MA (2012) Biasing the content of hippocampal replay during sleep. Nat Neurosci 15:1439-1444. CrossRef Medline

Buzsáki G (1996) The hippocampo-neocortical dialogue. Cereb Cortex 6:81-92. CrossRef Medline

Cai DJ, Shuman T, Harrison EM, Sage JR, Anagnostaras SG (2009) Sleep deprivation and Pavlovian fear conditioning. Learn Mem 16:595-599. CrossRef Medline

Chapuis J, Wilson DA (2011) Bidirectional plasticity of cortical pattern recognition and behavioral sensory acuity. Nat Neurosci 15:155-161. CrossRef Medline

Chen CF, Barnes DC, Wilson DA (2011) Generalized vs. stimulus-specific learned fear differentially modifies stimulus encoding in primary sensory cortex of awake rats. J Neurophysiol 106:3136-3144. CrossRef Medline

Costa-Miserachs D, Portell-Cortés I, Torras-Garcia M, Morgado-Bernal I (2003) Automated sleep staging in rat with a standard spreadsheet. J Neurosci Methods 130:93-101. CrossRef Medline

Datta S, O’Malley MW (2013) Fear extinction memory consolidation requires potentiation of pontine-wave activity during REM sleep. J Neurosci 33:4561-4569. CrossRef Medline

Dias BG, Ressler KJ (2014) Parental olfactory experience influences behavior and neural structure in subsequent generations. Nat Neurosci 17:8996. CrossRef Medline

Diekelmann S, Wilhelm I, Born J (2009) The whats and whens of sleep- dependent memory consolidation. Sleep Med Rev 13:309-321. CrossRef Medline

Diekelmann S, Büchel C, Born J, Rasch B (2011) Labile or stable: opposing consequences for memory when reactivated during waking and sleep. Nat Neurosci 14:381-386. CrossRef Medline

Ego-Stengel V, Wilson MA (2010) Disruption of ripple-associated hippocampal activity during rest impairs spatial learning in the rat. Hippocampus 20:1-10. CrossRef Medline

Fanselow MS, Gale GD (2003) The amygdala, fear, and memory. Ann N Y Acad Sci 985:125-134. CrossRef Medline

Fletcher ML, Wilson DA (2003) Olfactory bulb mitral-tufted cell plasticity: odorant-specific tuning reflects previous odorant exposure. J Neurosci 23:6946-6955. Medline

Funk D, Amir S (2000) Enhanced fos expression within the primary olfactory and limbic pathways induced by an aversive conditioned odor stimulus. Neuroscience 98:403-406. CrossRef Medline

Gais S, Plihal W, Wagner U, Born J (2000) Early sleep triggers memory for early visual discrimination skills. Nat Neurosci 3:1335-1339. CrossRef Medline

Girardeau G, Benchenane K, Wiener SI, Buzsáki G, Zugaro MB (2009) Selective suppression of hippocampal ripples impairs spatial memory. Nat Neurosci 12:1222-1223. CrossRef Medline

Gottfried JA, Dolan RJ (2004) Human orbitofrontal cortex mediates extinction learning while accessing conditioned representations of value. Nat Neurosci 7:1144-1152. CrossRef Medline

Haberly LB (2001) Parallel-distributed processing in olfactory cortex: new insights from morphological and physiological analysis of neuronal circuitry. Chem Senses 26:551-576. CrossRef Medline

Hasselmo ME, Barkai E (1995) Cholinergic modulation of activity-dependent synaptic plasticity in the piriform cortex and associative memory function in a network biophysical simulation. J Neurosci 15:6592-6604. Medline

Hasselmo ME, McGaughy J (2004) High acetylcholine levels set circuit dynamics for attention and encoding and low acetylcholine levels set dynamics for consolidation. Prog Brain Res 145:207-231. CrossRef Medline

Hauner KK, Howard JD, Zelano C, Gottfried JA (2013) Stimulus-specific enhancement of fear extinction during slow-wave sleep. Nat Neurosci 16:1553-1555. CrossRef Medline

Hegoburu C, Sevelinges Y, Thévenet M, Gervais R, Parrot S, Mouly AM (2009) Differential dynamics of amino acid release in the amygdala and olfactory cortex during odor fear acquisition as revealed with simultaneous high temporal resolution microdialysis. Learn Mem 16:687-697. CrossRef Medline

Huber R, Ghilardi MF, Massimini M, Tononi G (2004) Local sleep and learning. Nature 430:78-81. CrossRef Medline

Isaacson JS (2010) Odor representations in mammalian cortical circuits. Curr Opin Neurobiol 20:328-331. CrossRef Medline

Issa EB, Wang X (2011) Altered neural responses to sounds in primate primary auditory cortex during slow-wave sleep. J Neurosci 31:2965-2973. CrossRef Medline

Ji D, Wilson MA (2007) Coordinated memory replay in the visual cortex and hippocampus during sleep. Nat Neurosci 10:100-107. CrossRef Medline

Johnson BA, Leon M (2007) Chemotopic odorant coding in a mammalian olfactory system. J Comp Neurol 503:1-34. CrossRef Medline

Johnson DM, Illig KR, Behan M, Haberly LB (2000) New features of connectivity in piriform cortex visualized by intracellular injection of pyramidal cells suggest that "primary" olfactory cortex functions like "association" cortex in other sensory systems. J Neurosci 20:6974-6982. Medline

Kapur A, Haberly LB (1998) Duration of NMDA-dependent synaptic potentiation in piriform cortex in vivo is increased after epileptiform bursting. J Neurophysiol 80:1623-1629. Medline

Karlsson MP, Frank LM (2009) Awake replay of remote experiences in the hippocampus. Nat Neurosci 12:913-918. CrossRef Medline

Kass MD, Rosenthal MC, Pottackal J, McGann JP (2013) Fear learning enhances neural responses to threat-predictive sensory stimuli. Science 342 : 1389-1392. CrossRef Medline

Kumar G, Juhász C, Sood S, Asano E (2012) Olfactory hallucinations elicited by electrical stimulation via subdural electrodes: effects of direct stimulation of olfactory bulb and tract. Epilepsy Behav 24:264-268. CrossRef Medline

Lansink CS, Goltstein PM, Lankelma JV, McNaughton BL, Pennartz CM 
(2009) Hippocampus leads ventral striatum in replay of place-reward information. PLoS biology 7:e1000173. CrossRef Medline

Larson J, Wong D, Lynch G (1986) Patterned stimulation at the theta frequency is optimal for the induction of hippocampal long-term potentiation. Brain Res 368:347-350. CrossRef Medline

Li W, Howard JD, Parrish TB, Gottfried JA (2008) Aversive learning enhances perceptual and cortical discrimination of indiscriminable odor cues. Science 319:1842-1845. CrossRef Medline

Linster C, Maloney M, Patil M, Hasselmo ME (2003) Enhanced cholinergic suppression of previously strengthened synapses enables the formation of self-organized representations in olfactory cortex. Neurobiol Learn Mem 80:302-314. CrossRef Medline

Linster C, Menon AV, Singh CY, Wilson DA (2009) Odor-specific habituation arises from interaction of afferent synaptic adaptation and intrinsic synaptic potentiation in olfactory cortex. Learn Mem 16:452-459. CrossRef Medline

Lovitz AM, Sloan AM, Rennaker RL, Wilson DA (2012) Complex mixture discrimination and the role of contaminants. Chem Senses 37:533-540. CrossRef Medline

Manabe H, Kusumoto-Yoshida I, Ota M, Mori K (2011) Olfactory cortex generates synchronized top-down inputs to the olfactory bulb during slow-wave sleep. J Neurosci 31:8123-8133. CrossRef Medline

Maquet P (2001) The role of sleep in learning and memory. Science 294: 1048-1052. CrossRef Medline

Maren S (2011) Seeking a spotless mind: extinction, deconsolidation, and erasure of fear memory. Neuron 70:830-845. CrossRef Medline

Marshall L, Helgadóttir H, Molle M, Born J (2006) Boosting slow oscillations during sleep potentiates memory. Nature 444:610-613. CrossRef Medline

Molle M, Yeshenko O, Marshall L, Sara SJ, Born J (2006) Hippocampal sharp wave-ripples linked to slow oscillations in rat slow-wave sleep. J Neurophysiol 96:62-70. CrossRef Medline

Mouly AM, Vigouroux M, Holley A (1985) On the ability of rats to discriminate between microstimulations of the olfactory bulb in different locations. Behav Brain Res 17:45-58. CrossRef Medline

Murakami M, Kashiwadani H, Kirino Y, Mori K (2005) State-dependent sensory gating in olfactory cortex. Neuron 46:285-296. CrossRef Medline

Myers KM, Davis M (2007) Mechanisms of fear extinction. Molecular psychiatry 12:120-150. CrossRef Medline

Patil MM, Hasselmo ME (1999) Modulation of inhibitory synaptic potentials in the piriform cortex. J Neurophysiol 81:2103-2118. Medline

Pavesi E, Gooch A, Lee E, Fletcher ML (2012) Cholinergic modulation during acquisition of olfactory fear conditioning alters learning and stimulus generalization in mice. Learn Mem 20:6-10. CrossRef Medline

Pavlides C, Winson J (1989) Influences of hippocampal place cell firing in the awake state on the activity of these cells during subsequent sleep episodes. J Neurosci 9:2907-2918. Medline

Poo C, Isaacson JS (2011) A major role for intracortical circuits in the strength and tuning of odor-evoked excitation in olfactory cortex. Neuron 72:41-48. CrossRef Medline
Rabin MD (1988) Experience facilitates olfactory quality discrimination. Percept Psychophys 44:532-540. CrossRef Medline

Rasch B, Büchel C, Gais S, Born J (2007) Odor cues during slow-wave sleep prompt declarative memory consolidation. Science 315:1426-1429. CrossRef Medline

Rolls A, Makam M, Kroeger D, Colas D, de Lecea L, Heller HC (2013) Sleep to forget: interference of fear memories during sleep. Molecular psychiatry 18:1166-1170. CrossRef Medline

Roman F, Staubli U, Lynch G (1987) Evidence for synaptic potentiation in a cortical network during learning. Brain Res 418:221-226. CrossRef Medline

Roth TL, Raineki C, Salstein L, Perry R, Sullivan-Wilson TA, Sloan A, Lalji B, Hammock E, Wilson DA, Levitt P, Okutani F, Kaba H, Sullivan RM (2013) Neurobiology of secure infant attachment and attachment despite adversity: a mouse model. Genes Brain Behav 12:673-680. CrossRef Medline

Sahay A, Wilson DA, Hen R (2011) Pattern separation: a common function for new neurons in hippocampus and olfactory bulb. Neuron 70:582-588. CrossRef Medline

Skaggs WE, McNaughton BL (1996) Replay of neuronal firing sequences in rat hippocampus during sleep following spatial experience. Science 271: 1870-1873. CrossRef Medline

Sotres-Bayon F, Cain CK, LeDoux JE (2006) Brain mechanisms of fear extinction: historical perspectives on the contribution of prefrontal cortex. Biol Psychiatry 60:329-336. CrossRef Medline

Steriade M (2006) Grouping of brain rhythms in corticothalamic systems. Neuroscience 137:1087-1106. CrossRef Medline

Stevenson RJ (2001) Associative learning and odor quality perception: how sniffing an odor mixture can alter the smell of its parts. Learn Motiv 32:154-177. CrossRef

Stickgold R, Walker MP (2007) Sleep-dependent memory consolidation and reconsolidation. Sleep Med 8:331-343. CrossRef Medline

Sutherland GR, McNaughton B (2000) Memory trace reactivation in hippocampal and neocortical neuronal ensembles. Curr Opin Neurobiol 10: 180-186. CrossRef Medline

Suzuki N, Bekkers JM (2006) Neural coding by two classes of principal cells in the mouse piriform cortex. J Neurosci 26:11938-11947. CrossRef Medline

Tononi G (2009) Slow wave homeostasis and synaptic plasticity. J Clin Sleep Med 5:S16-19. Medline

Uchida N, Takahashi YK, Tanifuji M, Mori K (2000) Odor maps in the mammalian olfactory bulb: domain organization and odorant structural features. Nat Neurosci 3:1035-1043. CrossRef Medline

Wilson DA (2010) Single-unit activity in piriform cortex during slow-wave state is shaped by recent odor experience. J Neurosci 30:1760-1765. CrossRef Medline

Wilson DA, Stevenson RJ (2006) Learning to smell: olfactory perception from neurobiology to behavior. Baltimore: Johns Hopkins UP.

Wilson DA, Sullivan RM (2011) Cortical processing of odor objects. Neuron 72:506-519. CrossRef Medline

Wilson DA, Best AR, Sullivan RM (2004) Plasticity in the olfactory system: lessons for the neurobiology of memory. Neuroscientist 10:513-524. CrossRef Medline 